\title{
Dinâmicas de grupo no romance Selam Berlin, de Y. Kara
}

\section{Dionei Mathias*}

\begin{abstract}
Resumo: O romance Selam Berlin foi publicado em 2003, pela escritora Yadé Kara, condecorada com o prêmio Adelbert-von-Chamisso de 2004. O enredo trata de um jovem alemão de origem turca, Hasan Kazan, que em sua volta a Berlim interage com diferentes grupos sociais: os vizinhos idosos, o membro familiar socializado na cultura dominante e, por fim, os representantes do mundo artístico. Sua alteridade étnica dentro do universo ficcional desencadeia diferentes reações. Nesse sentido, este artigo pretende discutir a interação do protagonista com os três grupos mencionados e refletir sobre seu significado para a dinâmica de grupo.
\end{abstract}

Palavras-chave: Yadé Kara. Selam Berlin. Dinâmica de grupo.

Abstract: The novel Selam Berlin was published in 2003, by Yadé Kara, winner of the 2004 Adelbert-von-Chamisso-Prize. The plot shows a young German of Turkish origin, called Hasan Kazan, who after going back to Berlin interacts with different social groups: the elderly neighbours, the family member socialized in the dominant culture and representatives of the artistic world. His ethnic alterity within this fictional world triggers different reactions. In this sense, this article aims to discuss the protagonist's interaction with the three groups mentioned before and make some considerations on its meaning for the group dynamics.

Keywords: Yadé Kara. Selam Berlin. Group dynamics.

Zusammenfassung: Der Roman Selam Berlin wurde 2003 von Yadé Kara, Adelbert-vonChamisso-Preis-Trägerin des Jahres 2004, veröffentlicht. Es geht in der Handlung um einen jungen Deutschen türkischen Ursprungs, Hasan Kazan, der nach seiner Rückkehr nach Berlin mit unterschiedlichen Gruppen interagiert: mit Nachbarn höheren Alters, Familienangehörigen, die in der dominanten Kultur sozialisiert wurden, und zuletzt auch mit Menschen aus dem Kunstmilieu. Seine ethnische Alterität innerhalb dieser fiktionalen Welt löst unterschiedliche Reaktionen aus. In diesem Sinne werden in diesem Aufsatz die Interaktionen der Hauptfigur mit den drei genannten Gruppen und deren Bedeutung für die Gruppendynamik diskutiert.

Schlüsselwörter: Yadé Kara. Selam Berlin. Gruppendynamik.

\footnotetext{
* Doutor em Letras pela Universidade de Hamburgo, Alemanha e pela Universidade Federal do Paraná. Professor do Departamento de Letras Estrangeiras Modernas e do Programa de Pós-Graduação em Letras da Universidade Federal de Santa Maria. http://orcid.org/oooo-0001-8415-1460
}

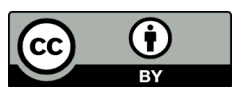




\section{Introdução}

Yadé Kara, autora alemã de origem turca, nasceu em 1965 na Turquia e cresceu na Alemanha ainda dividida, na parte ocidental de Berlim. Completando quase quarenta anos, Kara lança em 2003 seu primeiro romance: Selam Berlin (aqui traduzido livremente como 'Saudações Berlim'). Com elementos típicos do romance de formação, o enredo apresenta os 'anos de aprendizado' do jovem Hasan Kazan, um rapaz de dezenove anos, socializado na Alemanha e na Turquia e que, após concluir o ensino médio, decide voltar para Berlim para entrar na faculdade. Do mesmo modo como ele compara as duas metrópoles e seus espaços de trânsito díspares, ele também atenta para as diferenças nos comportamentos e nas formas de interação nos dois países. Sem idealizar nem uma, nem outra cultura, Hasan identifica as manobras comportamentais e suas dissimulações simbólicas em cada um dos contextos, procurando por formas de administração da diferença e por caminhos para otimizar os processos de interação.

Assim, seu processo de aprendizado passa por questões centrais dessa etapa existencial, como amizades, negociação de valores, pertencimento, sexualidade, mas também foca num ponto tipicamente importante para indivíduos com uma socialização bicultural, isto é, o arraigamento cultural e suas consequências para os processos de apropriação de realidade. Como Wilhelm Meister, Hasan Kazan interage com diferentes grupos sociais e negocia intepretações de realidade que vão nortear sua existência. Nesse sentido, o romance de Yadé Kara contribui não somente para a continuação desse subgênero novelístico que é o romance de formação, mas também cria novas tessituras para imaginar o espaço nacional e a cultura que estabelece os parâmetros para a articulação da voz. Além disso, como argumenta Hamazaki (2009), o romance encena uma outra realidade da Berlim que vai surgindo nos primeiros anos da reunificação.

Como o protagonista interage com grupos de diferentes faixas etárias e socializações culturais, o conceito de cultura se revela sumamente importante para compreender a lógica que marca as interações. Nesse sentido, entende-se cultura não como imanência nacional, isto é, como essência de um povo, como concebido por Herder "um pensamento central para o processo da gênese nacional no século XIX" 
(EAGLETON, 2005, p. 24), mas sim como vetores que, de certo modo, uniformizam comunicação, pensamento, emoções, comportamento e valores (HANSEN, 2003). Nisso, são as práticas de inclusão e exclusão que vão definindo os valores e as formas de comportamentos considerados adequados para um determinado espaço de interação.

Esses processos de homogeneização podem acontecer em escala nacional por meio de instituições públicas de impacto nacional e de mídias com ampla abrangência ou se restringir a médios ou pequenos grupos, caracterizados sempre pelo desejo de pertencimento a um determinado agrupamento social. Esse desejo de pertencimento se revela, em grande parte, responsável pela canalização da energia cognitiva, emocional, comunicacional ou acional do sujeito em direção a comportamentos similares ao grupo do qual deseja fazer parte. Uma vez parte do grupo e estabilizados os processos de legitimação, o sujeito reproduz e exige dos novos membros comportamentos semelhantes, produzindo, portanto, práticas de interpretação e apropriação de realidade.

Para a manutenção da identidade de grupo e, com isso, do potencial da sensação de pertencimento, a administração da diferença é um mecanismo imprescindível. A sensação de pertencimento obtida a partir da formação de grupos com práticas similares de concretização existencial depende da construção de mecanismos excludentes. Com isso, a diferença cultural tem um impacto não somente nas narrativas nacionais - como era o caso no século XIX; ela continua sendo imprescindível para uma necessidade básica da condição humana, já que, de certo modo, legitima a identificação do grupo.

Isso, contudo, não quer dizer que a diferença em si seja responsável pelas práticas de inclusão ou exclusão. Com efeito, muito depende do modo como cada sujeito ou cada grupo administra sua identidade pessoal ou de grupo. Em havendo crivos pessoais de interpretação e apropriação de realidade que permitam a convivência com a diferença, sem necessidade de exclusão, surge uma maior flexibilidade nas interações cotidianas e no modo como energias sociais são canalizadas. Se, do contrário, a narração de identidade estiver pautada pelo princípio da diferença, o olhar do sujeito vai focar nisso, a fim de garantir a coerência de sua narrativa. Com isso, o modo como a tessitura cultural está organizada depende, portanto, da maneira como cada sujeito ou cada grupo estabelece critérios para a manutenção da coesão, impondo regras de pertencimento. 
O romance Selam Berlin, de certo modo, encena essa dinâmica quando o jovem protagonista de origem turca volta a Berlim. Nesse retorno à cidade de sua socialização, o jovem Hasan interage com três agrupamentos diferentes, todos eles pertencentes a configurações culturalmente dominantes: os vizinhos idosos que participaram da guerra, o membro familiar socializado na cultura dominante e, por fim, os representantes do mundo artístico. Com isso, há três socializações culturais pautadas por configurações culturais e sedimentos ideológicos diferentes. Cada um dos representantes vai interagir de modo diferente, a fim de administrar seu desejo pessoal de coerência narrativa e pertencimento.

\section{Encontro entre gerações: o jovem “turco" e sobreviventes da guerra}

Logo ao chegar ao prédio onde mora a sua família, o protagonista encontra a senhora Wessel, a vizinha do lado. O casal Wessel, já em idade avançada, sobreviveu aos tormentos da segunda guerra mundial e vive, no presente diegético, num prédio que de resto é habitado exclusivamente por famílias estrangeiras:

No prédio da rua Adalbertstraße 8 os Wessel eram os únicos alemães, o resto: tudo da Anatólia. Cada andar era habitado por um grupo étnico. O pessoal de Istambul e outros grupos da parte europeia da Turquia ficaram com os andares superiores [...] Os Wessel moravam ao lado e não tinham filhos. Eles adotaram a mim e a Ediz como netos, na época quando a gente ia no primário. Eu subi as escadas e quando cheguei perto dela, ela abriu um sorriso largo. Sua cabeça tremia e os brincos dançavam loucos sob sua peruca marrom. 'Ah, nossa, o Hansi tá de volta'. Ela era uma daqueles que sempre me chamavam de Hansi, embora meu nome fosse Hasan Selim Khan Kazan (KARA, 2003, p. 35-36)․

\footnotetext{
1 "In dem Mietshaus Adalbertstraße 8 waren die Wessels die einzigen Deutschen, der Rest: lauter Anatolier. Jedes Stockwerk wurde von einer Volksgruppe bewohnt. Istanbuler und andere Gruppen vom europäischen Teil der Türkei hatten sich in den oberen Etagen angesiedelt. [...] Die Wessels wohnten nebenan und hatten keine Kinder. Sie hatten Ediz und mich als ihre Enkel adoptiert, damals, als wir hier noch zur Grundschule gingen. Ich stieg die Treppe hinauf, und als ich nahe genug bei ihr war, strahlte sie. Ihr Kopf zitterte, und die goldenen Ohrringe tanzten wild unter ihrer braunen Perücke. »Ach neee, der Hansi is wieder da.« Sie war eine von denen, die mich immer Hansi nannten, obwohl ich Hasan Selim Khan Kazan hieß." (KARA, 2003, p. 35-36).
} 
O modo como ela recebe a Hasan está marcado por um empenho afetivo bastante grande, indicando um relacionamento profundo de respeito e acolhimento por ambas as partes. Dada a socialização ideológica da família Wessel durante o regime nazista, sua capacidade de conviver com a diferença causa estranhamento. Contudo, ao contrário das expectativas, há um envolvimento afetivo que enxerga o outro, antes de mais nada, como ser digno de investimento afetivo, não como membro de um grupo de estrangeiros. Esse pertencimento a um grupo que não é o próprio poderia legitimar a transformação do outro em objeto, assim bloquear qualquer direcionamento afetivo que deseje construir redes de coesão. Nesse caso, no entanto, o crivo da estrangeiridade não é adotado como modalidade de percepção. Por algum motivo, consciente ou inconsciente, a senhora Wessel aciona uma modalidade de percepção que permite enxergar semelhanças e elementos que a liguem a esse jovem, com aspecto de estrangeiro. Com efeito, a identidade de grupo parece deixar de ter um impacto no modo de interação para dar lugar a um foco de visão que enxerga o sujeito como tal e não como membro de um grupo coisificado, o qual deve ser excluído.

Dois motivos talvez pudessem ser elencados para explicar essa mudança na capacidade de enxergar o outro: a condição de minoria no prédio e a fragilização da idade. Ao habitar um espaço, no qual é o único que se diferencia por não apresentar uma conexão com outras culturas, o casal Wessel indiretamente se vê forçado a exercitar um olhar para a diferença, contudo não voltado para a construção de muros, mas sim em direção à identificação de narrações conjuntas e da organização de uma linha temporal onde esses membros estão presentes, participando ativamente da história e das identidades pessoais do casal. O segundo elemento, pautado pela fragilização da idade, mas incluindo também fenômenos de solidão e de isolamento social, parece predispor uma configuração afetiva que permite tecer ligações, produzindo investimentos de energia construtiva. Com isso, o estrangeiro deixa de ser representante de grupo cultural marcado pela alteridade, e se transforma em fonte de capital afetivo, sumamente importante para a sensação de pertencimento. Isto é, houve uma alteração no modo como a percepção cultural, com suas lógicas de inclusão e exclusão e, sobretudo, na percepção de potenciais de pertencimento, é administrada. 
A reação corporal da senhora, com o sorriso e os tremores, indica o grau de seu envolvimento. Seu interlocutor deixou de ser um representante abstrato de um outro grupo, para se transformar em alguém que faz parte ativa de sua história. Isso se reflete também na escolha do apelido para se dirigir a ele. A utilização do apelido certamente é controversa. Se por um lado pode representar uma forma de apagar a estrangeiridade do interlocutor, negando, portanto, o reconhecimento de um elemento central de sua condição existencial, por outro, parece representar também um indicador do desejo de criar práticas linguísticas especiais para mostrar o status de pertencimento a um círculo social mais íntimo, logo, afetivamente mais denso. O modo como Hasan reage, revela que ele reconhece essa estratégia e a aceita, apesar do seu conhecimento sobre a possibilidade de elisão da diferença.

Essa reconfiguração na lógica de administração de grupos e dos potenciais de pertencimento acaba por produzir uma dinâmica de interação, que permite uma tessitura de coesão social que vai muito além das trocas cotidianas de gentileza com atores sociais que transitam pelo mesmo espaço. Assim, quando a senhora Wessel se encontra num momento de extrema angústia e impotência, ela enxerga em Hasan um esteio:

\begin{abstract}
De repente, ela me parecia tão pequena e vulnerável; a vó Wessel que de resto sempre fora tão recalcitrante parecia acabada e fraca. »Vai dar tudo certo, vô Wessel vai ficar bom de novo. Coragem.» Eu segurei as sacolas de compras pra ela e ela se apoiou em mim [...] »E em que hospital ele está?« perguntei cheio de pena com seu susto e sua dor. «No hospital urrrbano«, dizia ela choramingando. Vó Wessel sempre rolava o r. Ela vinha da Silésia (KARA, 2003, p. 37). ${ }^{2}$
\end{abstract}

O primeiro tipo de apoio que Hasan pode fornecer é um apoio afetivo. Com efeito, o jovem contribui para recobrar a estabilização emocional que a senhora Wessel perde diante da hospitalização de seu marido. Nisso, o que está no centro do crivo de percepção não é a diferença, mas sim a dor e a fragilidade do outro. Dessa confluência

\footnotetext{
2 "Sie kam mir plötzlich so klein und hilflos vor, die sonst so aufmüpfige Oma Wessel sah mitgenommen und schwach aus. »Das wird schon wider, Opa Wessel kommt wieder auf die Beine. Kopf hoch.« Ich nahm ihr die Einkaufstüte ab, und sie stützte sich auf mich [...] »Und in welchem Krankenhaus liegt er?« fragte ich voller Teilnahme an ihrem Schreck und Schmerz. »Im Urrrban Krrankenhaus«, kam es weinerlich von ihr. Oma Wessel rollte das R immer so. Sie kam aus Schlesien.” (KARA, 2003, p. 37).
} 
de energia afetiva, surge uma forma de capital social que adota outros critérios de organização e interação social (BOURDIEU, 1983). A senhora Wessel investe, por meio de sua atenção, nessa modalidade e tece, com isso, uma rede que amortiza o impacto causado pela incerteza do futuro.

Da mesma forma como ela não adota o crivo da estrangeirização, Hasan tampouco se utiliza de rótulos simplificadores para definir o modo como interage com ela. A fim de evitar o estresse emocional e o empenho de energia que demanda essa interação, ele poderia percorrer o mesmo caminho da coisificação do outro, agora no caminho inverso. Ele, contudo, não o faz. Pelo contrário, Hasan opta por enxergar a diferença da velha senhora e transformar essa diferença num princípio de semelhança. Assim, quando menciona a origem silesiana e as idiossincrasias de pronúncia, ele indica que tem consciência da diferença. Isso possivelmente sirva como base para criar uma solidariedade pautada pela alteridade diante do horizonte da maioria naquele espaço social, mas pode representar também um conhecimento humano e uma maturidade nas práticas de percepção, que permitem ao sujeito vislumbrar formas de interação que não precisam instrumentalizar a diferença para criar muros narrativos. No lugar de uma coesão narrativa tecida a partir de configurações dicotômicas ou excludentes, surge um modelo que se pauta pelo desejo de enxergar o outro, independentemente de sua afiliação cultural, étnica ou social. Esse caminho de percepção também permanece diante de opiniões estereotipadas: "Embora o vô Wessel nunca tivesse estado na Turquia, ele sabia que turcos cavalgavam em camelos, usavam bombachas turcas e fumavam cachimbos de água" (KARA, 2003, p. 42)3. Hasan ironiza essa visão estereotipada, mas sabe, ao mesmo tempo, que o modo de interação adotado pelo casal não está marcado pelo princípio da exclusão. Nisso, ele diferencia entre chances de acesso ao conhecimento e comportamentos excludentes baseados em hostilidade.

\section{Membros da família e exigências culturais}

\footnotetext{
3 "Obwohl Opa Wessel nie in der Türkei war, wußte er, daß Türken auf Kamelen reiten, Pumphosen tragen und Wasserpfeife rauchen” (KARA, 2003, p. 42).
} 
O segundo exemplo de processo de interação e negociação de diferença se dá dentro do círculo de amizades, com representantes que tiveram uma socialização unicamente pautada pelos valores do espaço assim chamado ocidental, mais especificamente, Berlim ocidental. A família de Hasan tem um contato bastante frequente com o amigo também turco do pai, casado com a alemã Ingrid. Esses amigos praticamente substituem a família que ficou na Turquia e, portanto, ocupam um espaço afetivo de grande relevância, especialmente para os membros turcos desse círculo.

Ao contrário deles, Ingrid não experimenta a necessidade de permanecer na proximidade de pessoas com a socialização turca e, embora casada com um homem turco, apresenta dificuldades em adotar outro crivo de percepção e apropriação de realidade que não seja aquele de sua primeira socialização:

Ela insistia em que nós falássemos alemão na casa dela. Ela mesma não aprendeu turco. »Tinha öö, üüü demais, muito complicado«, era sempre sua desculpa. Todos nós tínhamos que nos adaptar a Ingrid. Na mesa, mamãe tinha que falar alemão quando pedia sal ou pimenta. Isso era artificial pra cacete. Por isso, raramente íamos à casa da Ingrid (KARA, 2003, p. 129). ${ }^{4}$

Como ela transita num espaço, em que a maioria tem a mesma socialização, ela não se vê confrontada tão frequentemente com reações de estranhamento, exigências muitas vezes hostis de legitimação da visão de mundo ou silenciamento nos processos de negociação de valores. Diante dessa experiência social, fica mais difícil adotar ou aprender a construir a realidade a partir de um outro crivo de percepção. Assim, a insistência na utilização da língua alemã num espaço privado, caracterizado por um alto empenho afetivo, ignora as necessidades socioafetivas dos outros membros desse círculo, o que parece revelar uma incapacidade de vislumbrar o horizonte do outro. Ao mesmo tempo que Ingrid impõe a utilização exclusiva de sua língua materna, ela, por outro lado, não se mostra disposta a aprender a língua da pessoa com quem escolheu viver ou dos amigos, em cuja casa circula. O argumento da complexidade linguística põe

\footnotetext{
4 "Sie bestand darauf, daß wir bei ihr zu Hause deutsch sprachen. Sie selber lernte kein Türkisch. »Es hat zuviel öö, üüü, zu kompliziert«, war immer ihre Ausrede. Wir alle mußten und auf Ingrid einstellen. Am Eßtisch mußte ich Mama auf deutsch um Salz und Pfeffer bitten. Das war so ätzend künstlich. Deshalb gingen wir selten zu Ingrid" (KARA, 2003, p. 129).
} 
termo à discussão, sem permitir que esse mesmo argumento valha para o caminho inverso.

Sabendo-se parte da maioria, esse posicionamento parece ter maior peso na legitimação, sugerindo que o modo de pensar defendido por Ingrid seria, de fato, a única maneira de conceber a realidade. Esta, contudo, acaba sendo construída a partir da visão de mundo do grupo majoritário, silenciando até mesmo o desejo de legitimar a utilização de um outro instrumento linguístico que não seja o oficial. Nisso, há um processo de negociação da diferença entre os dois grupos culturais. A diferença do grupo minoritário, porém, acaba por não ter nem poder, nem a habilidade para tecer uma rede de argumentação que legitime a permanência daquilo que difere da maioria.

Com isso, a concessão do capital afetivo da sensação de pertencimento está atrelada à submissão e aceitação das regras alheias, ao preço do apagamento ou, ao menos, do abafamento da própria diferença. Isto é, em desejando pertencer ao grupo, a condição é a utilização da língua majoritária, mesmo que isso contradiga as necessidades mais íntimas dos membros pertencentes aos grupos minoritários. A negociação da diferença que ocorre aqui não se mostra disposta a vislumbrar ou, muito menos, reconstruir o crivo de percepção da realidade do outro. O princípio que incide neste caso é a configuração do poder, legitimado pelo pertencimento ao grupo que define as regras do jogo naquele espaço de interação social.

Esse tipo de imposição obviamente tem um impacto na economia afetiva daqueles que se veem forçados à submissão. Para a mãe, que tem dificuldades com a língua alemã, a necessidade de se expressar num idioma com o qual não se sente confortável contém uma sensação de humilhação, ainda mais porque se trata de um espaço privado, não de um órgão oficial que normalmente assume uma linha dura mesmo, sem muitas concessões às práticas de gentileza. Essa sensação de humilhação se intensifica ainda para o filho, que transita sem dificuldades entre as duas culturas e reconhece a arbitrariedade desse comportamento direcionado a uma pessoa de grande importância afetiva em sua existência.

No lugar do enfrentamento e da hostilidade, contudo, a estratégia de resistência é o afastamento. Assim, as visitas se tornam mais escassas, evitando o confronto inevitável com o desrespeito. Isso acaba tendo um impacto também sobre a dinâmica de 
administração dos grupos. Se por um lado não há uma ruptura completa, o que implica a aceitação das imposições, por outro lado, o grupo acaba perdendo também seu poder como norte na concretização de ações, quando seus membros optam por outras formatações sociais, preferindo o afastamento e indicando um questionamento, ao menos parcial, das regras que ditam a lógica de inclusão e exclusão.

Paralelamente ao afastamento, surge, dentro do próprio núcleo familiar, uma consciência da diferença:

\begin{abstract}
»Ah, antes que eu esqueça, Ingrid convida vocês para o Natal. Para a ceia. Temos visita de Berlim Oriental. Parentes da Ingrid.«

»Ah, não, que surpresa! Desde quando a Ingrid nos deseja para uma refeição? Provavelmente a gente vai ter que trazer algo, isso é normal na Ingrid. Ela disponibiliza o espaço e os convidados têm autorização para trazer a comida. Que hospitalidade!«, debochava mamãe (KARA, 2003, p. 124).5
\end{abstract}

Assim, quando o marido de Ingrid convida a mãe de Hasan para a ceia de Natal, ela reage num tom de ironia, questionando abertamente as práticas de hospitalidade adotadas por ela. Nesse movimento irônico, muito próximo do potencial subversivo do dialogismo de Bakhtin (1987), a mãe empreende uma negociação de valores que norteiam a concretização da realidade, indicando que essa modalidade de interação não é aceitável na interpretação de realidade que ela utiliza como parâmetro existencial. $\mathrm{O}$ poder de determinação sobre as regras do jogo e, especialmente, sobre as modalidades de inclusão e exclusão acaba relativizado, diante do reconhecimento da quebra de um valor, ao qual o interlocutor atribui grande importância.

Nessa tomada de consciência sobre práticas culturais e normas de inclusão, encontra-se o motor inicial da reavaliação da dinâmica de grupos. O potencial subversivo que parte da interpretação da mãe abre as portas para novas formas de conceber a realidade, no espaço hegemônico. Se a primeira geração de imigrantes ainda

\footnotetext{
5 “»Ach, ehe ich es vergesse, Ingrid lädt euch zu Weihnachten ein. Zum Festessen. Wir haben Besuch aus Ostberlin. Verwandtschaft von Ingrid.«

»Ach nein, das ist aber eine Überraschung! Seit wann will denn Ingrid uns zum Essen haben? Wahrscheinlich müssen wir was mitbringen, das ist doch so üblich bei Ingrid. Sie stellt die Räume, und die Gäste dürfen das Essen mitbringen. Was für eine Gastfreundschaft!« spottete Mama” (KARA, 2003, p. 124).
} 
opta por aceitar em silêncio desrespeitos e arbitrariedades, a segunda geração, isto é, personagens como Hasan com uma socialização dupla e, portanto, com um conhecimento mais amplo sobre modalidades de interação, começa a questionar as formas como as interações sociais são organizadas, instaurando e impondo novas regras de pertencimento e organização de grupos.

\section{O mundo dos artistas e o desafio dos estereótipos}

Em suas andanças por Berlim e em suas tentativas de criar um espaço pessoal de desenvolvimento, Hasan acaba sendo confrontado com estereótipos, em situações bastante inusitadas. Assim, quando vai procurar uma vaga numa república, a fim de se distanciar da atmosfera pesada que envolve a separação dos pais, o jovem passa por um interrogatório, com perguntas inesperadas:

»Então, o que a gente queria era sua promessa que você não vai ter visitas de família com oito crianças, churrascos na sacada ou matanças de carneiro na banheira!«

Fiquei sem ar. Engoli em seco. Que bosta ela tava falando aí?! Eu não acreditava no que estava ouvindo.

Antes que eu pudesse dizer algo, ela disse: »Então, você entende, né....» Ela estava procurando pelas palavras certas. »Turcos têm famílias tão grandes e .... comem muita carne. Você precisa saber que nós somos não-fumantes e vegetarianas«" (KARA, 2003, p. 201-202). ${ }^{6}$

Trata-se de jovens mulheres oriundas da província, tentando sua sorte em Berlim. Como Hasan, elas vão trabalhar numa produção cinematográfica, isto é, estão envolvidas com arte e exercícios de percepção. Apesar desse capital cultural e, portanto, pertencerem à classe intelectualizada, elas não conseguem se distanciar de imagens estereotipadas que circulam em seus meios sociais. A hesitação com que formulam suas

\footnotetext{
6 “»Also, was wir wollen, ist dein Wort, daß du keine Familienbesuche mit acht Kindern, Grillparties auf dem Balkon oder Hammelschlachten in der Badewanne veranstaltest!«"

Mir blieb die Luft weg. Ich schluckte schwer. Was laberte die da?! Ich traute meinen Ohren nicht.

Ehe ich was sagen konnte, sagte sie:»Na ja, du verstehst doch....» Sie suchte nach den richtigen Worten. »Türken haben so...so große Familien und...essen viel Fleisch. Du mußt wissen, wir sind Nichtraucher und Vegetarier...«" (KARA, 2003, p. 201-202).
} 
perguntas, parece sugerir cuidado e tato, quando, na verdade, serve para resguardar a própria imagem e a imagem do grupo.

Por meio de suas falas e com suas expectativas tácitas, elas criam agrupamentos, traçando uma linha que separa o pertencimento delas do agrupamento em que incluem Hasan. Com efeito, o olhar que investiga a realidade empreende um movimento inconsciente de etnização da realidade; Fachinger (2007) fala de um olhar etnográfico ("ethnographic gaze”). A construção conceptual dos muros étnicos, por sua vez, aciona imagens que circulam naquele espaço social e levam as jovens a se certificarem que Hasan não é praticante dos rituais que elas conectam às minorias de origem turca na Alemanha. Nisso, elas não se questionam até que ponto as imagens - muitas vezes veiculadas pelos meios de comunicação de massa, especialmente também tabloides menos interessados em diferenciar - podem realmente representar esse grupo que elas optam por diferenciar do seu. Isso exigiria um exercício de percepção e construção da realidade, para o qual ainda não têm a maturidade cultural, tampouco o desejo de investir energia para trilhar outros caminhos de construção do conhecimento sobre a realidade.

Vale ressaltar aqui que as respostas dadas por Hasan têm um impacto sobre as chances de obter um lugar na república. Isso se revela como algo extremamente importante, por já ter recebido recusas anteriormente, quando o dono se dá conta de sua origem turca. Nesse sentido, a lógica de agrupamentos e de engavetamentos por origem étnica implica também em chances de concretização existencial. O que resta a Hasan é se submeter aos estereótipos e assegurar que não vai realizar nem festanças, nem matanças. Do contrário, suas chances e seu potencial de agência se reduziriam expressivamente.

Como a mãe no contexto da família, Hasan também adota a ironia, indicando seu conhecimento sobre as lógicas inconscientes de interação:

Elas vinham do oci-mundo (Wessiland) e conheciam turcos somente de vista. Elas queriam atualizar seus conhecimentos científicos sobre turcos. Quando voltassem para suas cidadezinhas, tinham uma vantagem em 
relação aos outros ocis. Já sabiam tudo sobre turcos e multicultis (KARA, 2003, p. 205 $)^{7}$.

Em sua ironia, Hasan deixa claro que o suposto esclarecimento tem uma função social de representação e administração das hierarquias pautadas pelos conhecimentos, mas sem grande impacto para as interações concretas do cotidiano. Nesse movimento, ele se assemelha à discussão que Hall (1992) faz sobre as arbitrariedades do termo “ocidente”.

Essa dinâmica de inclusão e exclusão, atrelada ao mercado de distribuição de chances também volta a incidir, quando Hasan recebe uma chance para atuar num filme. A atuação, contudo, está condicionada à submissão ao estereótipo do imigrante turco: “O que Wolf queria estava claro. Um turco de fliperama com faca e ligado em família” (KARA, 2003, p. 253) ${ }^{8}$. Quando Hasan começa a utilizar o dialeto berlinense, Wolf, o diretor, o interrompe para pedir que fale turco. Do mesmo modo como as jovens da república, também o diretor já tem uma imagem pronta e exige de seu interlocutor que a desempenhe. Hasan, contudo, tem consciência do que está acontecendo e vai ao encontro das expectativas geradas pelos estereótipos, a fim de assegurar suas chances, como aponta Ege (2016).

Se na primeira situação a exigência era não apresentar qualquer resquício de cultura minoritária, no segundo exemplo lhe exigem que internalize o papel do jovem estrangeiro dividido entre as culturas, com dificuldades de adaptação aos valores assim chamados ocidentais. Se antes foi a chance no mercado imobiliário, neste contexto, trata-se de oportunidades no mercado profissional. Em ambos os casos, o conhecimento sobre as regras que imperam na lógica de formação de grupos se revela como essencial, pois somente com esse conhecimento sobre as arbitrariedades sociodiscursivas é que Hasan obtém as chances que, do contrário, lhe seriam recusadas.

\footnotetext{
7 "Sie kamen aus Wessiland und kannten Türken nur vom Sehen. Sie wollten ihre wissenschaftlichen Kenntnisse über Türken auf dem aktuellen Stand halten. Wenn sie zu Besuch in ihren Dörfern waren, dann hatten sie den anderen Wessis dort etwas voraus. Sie hatten den vollen Durchblick in Sachen Türken und Multikulti." (KARA, 2003, p. 205). A palavra "oci-mundo" tenta recriar o termo irônico "Wessiland", isto é, terra do ocidente. O mesmo vale para "multicultis", termo também irônico que remonta à discussão sobre multiculturalismo.

8 "Was Wolf wollte, war klar. Einen Spielautomaten-Türken mit Messer und Familiensinn" (KARA, 2003, p. 253).
} 


\section{Considerações finais}

Os três grupos analisados interagem cada um com sua lógica própria, administrando a diferença como critério para a inclusão ou exclusão do grupo. Em cada um dos três grupos, há uma quebra de expectativa, revelando configurações inesperadas no modo como energias afetivas e pertencimentos são canalizados. Assim, o primeiro grupo, representado pelo casal idoso que passou pelas experiências da guerra e pela ideologia nazista, surpreende ao desenvolver um relacionamento afetuoso com Hasan e sua família. Surpreende, pois os relatos sobre xenofobia oriundos de grupos neonazistas proliferam tanto no eixo extradiegético como no universo ficcional, incluindo aqui um episódio no romance Selam Berlin, no qual um amigo de Hasan é atacado por neonazista e sua amiga assediada de forma covarde.

No segundo grupo, o qual envolve membros da família, a expectativa seria um comportamento mais flexível e aberto à diferença, acolhendo-a e estimulando sua presença no círculo familiar. O que acontece, contudo, é exatamente o oposto. No lugar da afirmação da diferença, há práticas de silenciamento da alteridade e exigências de conformação com a cultura dominante, como critério de inclusão. Isso também vale para o grupo de atores sociais supostamente mais esclarecidos e envolvidos no mundo das artes. No lugar da diferenciação e do exercício de percepção esforçado em enxergar o que está entre os polos dicotômicos, há um movimento de imposição e reprodução de imagens estereotipadas.

O que o romance definitivamente mostra é que o pertencimento a um determinado agrupamento social não é suficiente para afirmar como cada um de seus membros vai administrar a diferença como critério de inclusão e exclusão. Com efeito, o romance desconstrói todas as expectativas e revela comportamentos inesperados. Em todas as configurações, contudo, a lógica do pertencimento incidiu sobre as decisões de incluir ou excluir. Diante desse cenário, o título do romance é uma piscadela crítica, recriando ficcionalmente esse espaço tão importante para o imaginário nacional desse espaço cultural. 


\section{Referências}

BAKHTIN, Mikhail. A cultura popular na Idade Média e no Renascimento: o contexto de François Rabelais. Tradução: Yara Frateschi Vieira. São Paulo: Hucitec, 1987.

BOURDIEU, Pierre. Ökonomisches Kapital, kulturelles Kapital, soziales Kapital. In: KRECKEL, Reinhard (Ed.). Soziale Ungleichheiten. Göttingen: Otto Schwartz, 1983, p. $183-198$.

EAGLETON, Terry. A ideia de cultura. Tradução: Sandra Castello Branco. São Paulo: Editora UNESP, 2005.

EGE, Muzeyyen. "Berliner Mauerfall und Grenzüberschreitungen im urbanen Raum.Identitätssuche in den Romanen Selam Berlin von Yade Kara und Eduards Heimkehr von Peter Schneider. In: Orbis Litterarum, 71 (2), 2016, p. 142-162.

FACHINGER, Petra. “A New Kind of Creative Energy: Yade Kara’s Selam Berlin and Fatih Akin's Kurz und Schmerzlos and Gegen die Wand. In: German Life and Letters, 6o (2), 2007, p. 243-26o.

HALL, Stuart. "The West and the Rest: Discourse and Power". In: S. HALL; B. GIEBEN (eds). Formations of Modernity. Cambridge: Polity, 1992, p. 275-320.

HAMAZAKI, Keiko. "Der andere Blick auf Berlin. Zu dem Roman Selam Berlin. In: Language, Culture and Communication, v. 1, 2009, p. 159-165.

HANSEN, Klaus P. Kultur und Kulturwissenschaften. Tübingen e Basel: A. Francke Verlag, 2003.

KARA, Yadé. Selam Berlin. Zürich: Diogenes Verlag, 2003.

Recebido em 15/04/2020. Aprovado em 19/o9/2020. 